Šefik Behrem $\bowtie$

Bahrudin Hrnjica

https://doi.org/10.21278/TOF.45Si1008421

ISSN 1333-1124

eISSN 1849-1391

\title{
RESULTS OF HEAT TRANSFER COEFFICIENT ESTIMATION DURING THE QUENCHING OF CYLINDRICAL SAMPLES IN AQUEOUS SOLUTIONS
}

\begin{abstract}
Summary
The paper presented the results of the heat transfer coefficient estimation in the process of two-dimensional axially symmetric quenching of cylindrical steel samples in aqueous $40{ }^{\circ} \mathrm{C}$ solutions. One aqueous solution had $5 \%$ and the other one $25 \%$ of Aquatensid BW. Such solutions allow the rate of cooling of steel quenching less than the one in clean water, and higher than the one in thermal oils. The experimental setup consisted of quenching three dimensionally different cylindrical probes into two different quenchants. The position of the thermocouples inside each probe, the aqueous solution streaming around the probe and the construction of the cooling bath conditioned the thermodynamic setting of the problem.

The mathematical setting of the problem was based on thermodynamic assumption of twodimensional axially symmetric, nonlinear and nonstationary heat conduction. The position of the thermocouples conditioned the inverse way of the problem solving and it led to an approximate estimation of an unknown heat transfer coefficient. During the task solving the compute model used the experimental results of the temperature measurements for the minimisations of the square deviation between the calculated and measured temperatures in one position and moment of time. The analysis of the obtained results during the quenching of cylindrical probes in aqueous solutions was compared to the results obtained when quenching in pure water.
\end{abstract}

Key words: $\quad$ probe, aqueous solution, quenching, estimation, heat transfer coefficient

\section{Problem description}

A cylinder of diameter $D \in\{25,50,75\} \mathrm{mm}$, height $H \in\{100,150,225\}$ and initial temperature $\approx 850{ }^{\circ} \mathrm{C}$ is vertically immersed, at the speed of $0.025 \mathrm{~m} / \mathrm{s}$, into the bottom upstream encountering a quenchant that spun to the cylinder at the speed of $0.336 \mathrm{~m} / \mathrm{s}$. During the immersion and stopping of the cylinder, continuously in time, the four temperatures inside the cylinder were measured to their equilibrium state using four thermocouples $(1,2,3,4)$ in the probe $\phi 25 \times 50 \mathrm{~mm}$ as shown in Figure 1. Equivalent positions of the thermocouples in the probe $\phi 50 \times 150 \mathrm{~mm}$ are 5,6,7 and 8, while in the probe $\phi 75 \times 225 \mathrm{~mm}$ they are 9,10,11 and 12 . Figure 1 schematically illustrates the problem described with the direction of movement of two steam fronts formed on the test cylinder bases. Based on the results measured in the probes' positions $1,2,4$, then 5,6,8 and 9,10,12 nearer to the external surface of the probe estimated heat transfer coefficient was obtained. 


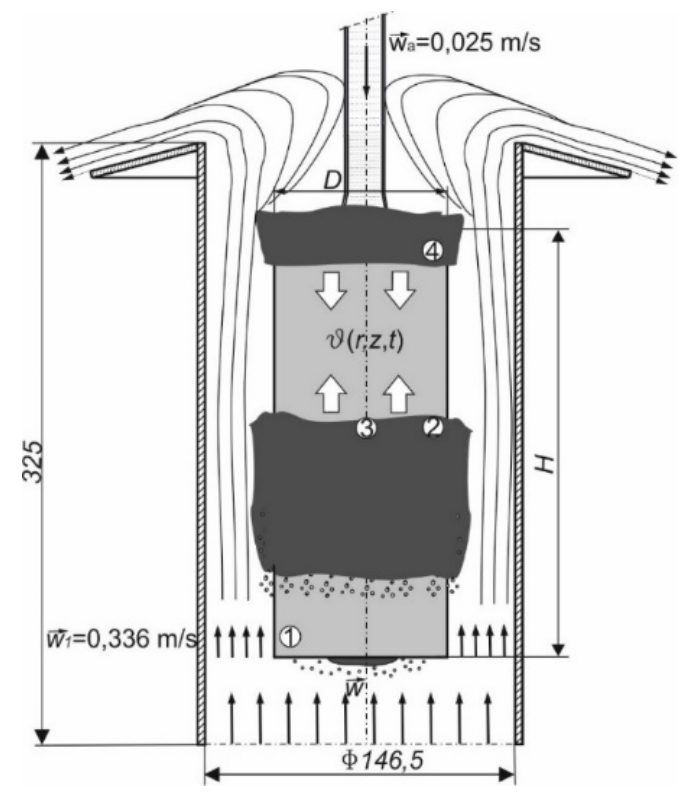

Fig. 1 Schematic drawing of the problem

\section{Experimental setup}

According to [1] and [4] the experimental setup consists of quenching three dimensionally different cylindrical probes. The material of the probes was AISI 304 steel which had no crystalline conversions. Steel quenchants were $5 \%$ and $25 \%$ solutions of Aquatensid $\mathrm{BW}$ in the water at $40{ }^{\circ} \mathrm{C}$. Aquatensid $\mathrm{BW}$ is a synthetic concentrate that dissolves in water at temperatures higher than $30{ }^{\circ} \mathrm{C}$. Aquatensid $\mathrm{BW}$ is a green viscous liquid with a density of $1080 \mathrm{~kg} / \mathrm{m}^{3}$ at $20{ }^{\circ} \mathrm{C}$ with a specific heat capacity of $3.8 \mathrm{~kJ} /(\mathrm{kgK})$ at temperature from 20 to $50{ }^{\circ} \mathrm{C}$ and kinematic viscosity of $70010^{-6} \mathrm{~m}^{2} / \mathrm{s}$ at $20^{\circ} \mathrm{C}$. Quenchings were done under strictly controlled conditions same as in [1]. A complete schematic and realistic review of the measurement line was given in [1] and [4] while Figures 2 and 3 show a schematic and realistic review of a tubular-concentric cooling bath with an immersed test cylinder.

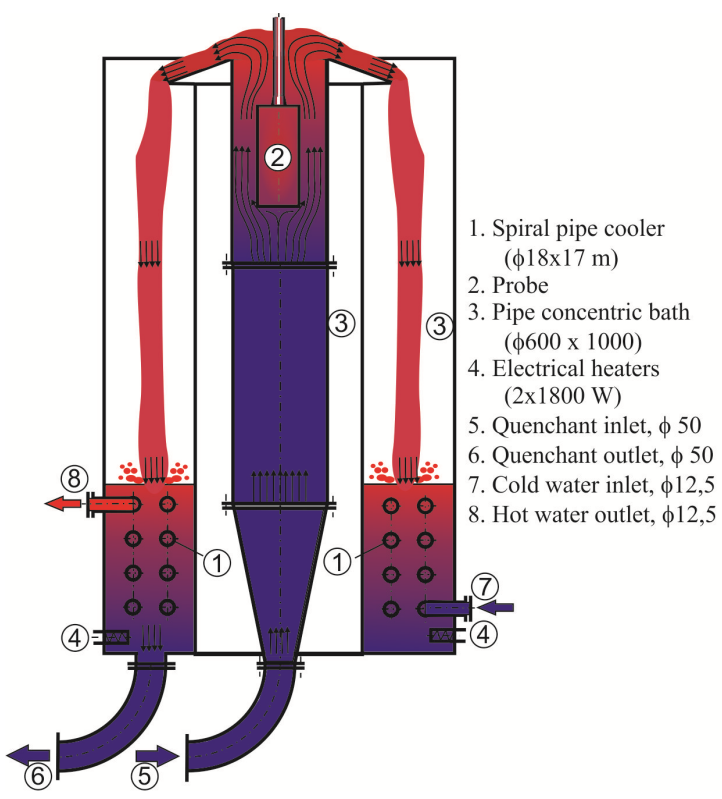

Fig. 2 Schematic drawing of pipe-concentric cooling bath

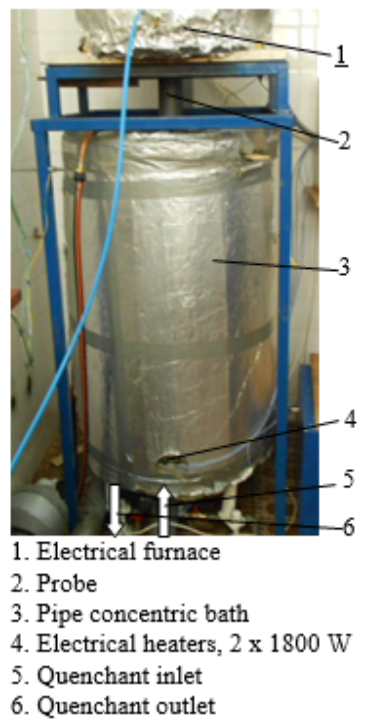

Fig. 3 Laboratory image of tubularconcentric cooling bath 

in Aqueous Solutions

Technical drawings of the test cylinders and the position of thermocouples were given in detail in [1] and [4]. The three measuring points in the probe were $1.5 \mathrm{~mm}$ below the cylinder surface lined by the cylinder height while the fourth one was in the centre of the cylinder. In the probe of $\phi 25 \times 100 \mathrm{~mm}$ the points marked were 1,2,3 and 4 shown in Figure 1. Equivalently in the probe of $\phi 50 \times 150 \mathrm{~mm}$ there were 5,6,7 and 8 and in the probe of $\phi 75 \times 225 \mathrm{~mm}$ there were $9,10,11$ and 12 . Data acquisition rate in time parallelly from four points inside the cylinder were two samples per second. The measurement results or cooling curves for all three probes in $5 \%$ and $25 \%$ of Aquatensid BW in water were shown in the Chapter Analysis and comparison of obtained results.

\section{The Mathematical setting of the problem}

\subsection{Thermodynamic problem setting}

According to the detailed explained assumptions from [1] and [4] the differential heat conduction equation describing these problems has such a form,

$$
\frac{\partial \vartheta}{\partial t}=\frac{\lambda(\vartheta)}{\rho(\vartheta) \cdot c(\vartheta)}\left[\frac{1}{r} \cdot \frac{\partial}{\partial r}\left(r \cdot \frac{\partial \vartheta}{\partial r}\right)+\frac{\partial}{\partial z}\left(\frac{\partial \vartheta}{\partial z}\right)\right] .
$$

To solve equation (1) the initial temperature field condition was $\vartheta(r, z, t=0) \approx 850{ }^{\circ} \mathrm{C}$ for each test cylinder. For the maximally simplified rectangular computational domain in Figure 4 the boundary conditions were given by the equations (2), (3), (4) and (5):

$$
\begin{aligned}
& \left(\frac{\partial \vartheta(r, z, t)}{\partial r}\right)_{r=0}=0, \\
& -\lambda(\vartheta)\left(\frac{\partial \vartheta}{\partial z}\right)=\alpha_{1}(0, t) \cdot\left(\vartheta(r, 0, t)-\vartheta_{\infty}\right), \quad z=0, \text { and } 0 \leq r<R, \\
& -\lambda(\vartheta)\left(\frac{\partial \vartheta}{\partial r}\right)=\alpha_{2}(z, t) \cdot\left(\vartheta(R, z, t)-\vartheta_{\infty}\right), \quad r=R, \text { and } 0<\mathrm{z}<H, \\
& -\lambda(\vartheta)\left(\frac{\partial \vartheta}{\partial z}\right)=\alpha_{3}(H, t) \cdot\left(\vartheta(r, H, t)-\vartheta_{\infty}\right), \quad z=H, \text { and } 0 \leq r<R .
\end{aligned}
$$

In the equations (3), (4) and (5) the unknown time current heat transfer coefficients on the corresponding rotational surfaces shown in Figure 4 and described by the function of the form $\alpha(z, t)(0 \leq z \leq H)$ define the thermodynamic boundary conditions of the third kind, while the equation (2) defines a boundary condition of second kind or an adiabatic boundary condition. 


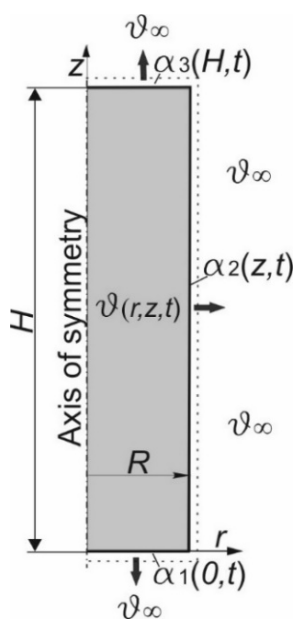

Fig. 4 Computing domain

The solution of the problem is reduced to a sufficiently accurate estimate of the unknown heat transfer coefficient applied on the outer surface of the cylinder. The physical properties of the test cylinder $\lambda(\vartheta), \rho(\vartheta)$ and $c(\vartheta)$ in the function of temperature are available in the standard base of the material of the used numerical software.

\subsection{Computer's solution algorithm}

The algorithm for solving the set problem arising from [5] and [6] was explained in detail in [4] and [1]. Figure 5 gives a flow chart of a simplified scheme of heat transfer coefficient estimation. The algorithm is based on a hybrid optimisation algorithm consisting of a combination of the non-dominant sorting genetic algorithm (NSGA II) [7] and the deterministic Levenberg-Marquardt method (LMM) [8]. Both algorithms use the condition of minimising the error between simulated and measured temperatures at the same point.

Figure 5 on the left side of the flow chart shows the NSGA II search loop while the right side of the flow chart shows LMM smoothing of the final results of the heat transfer coefficient.

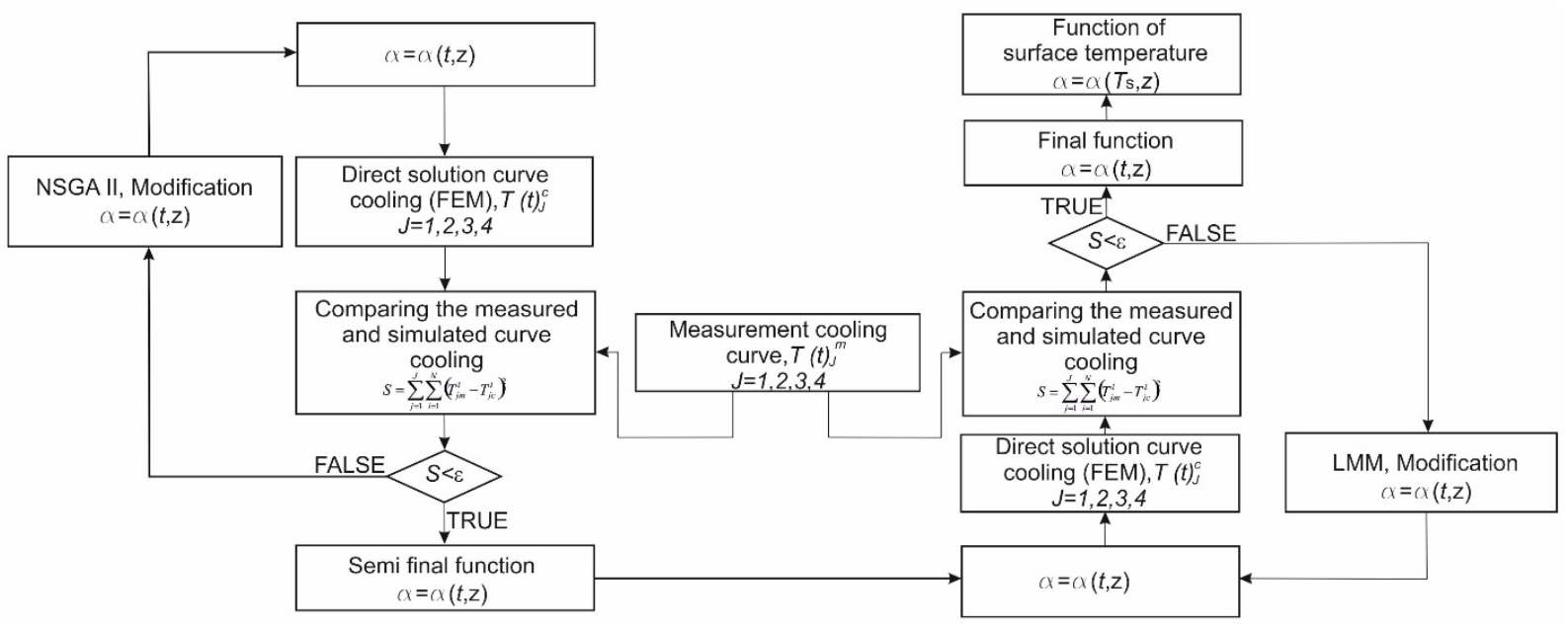

Fig. 5 Simplified solution algorithm

The current heat transfer coefficient $\alpha(t, z)$ was determined in such a way that three points on the outer surface of the probe were selected at the computational 2D domain. Time estimates of time functions $f_{1}(t), f_{2}(t)$ and $f_{3}(t)$ were selected horizontally opposite or near the measuring point as in Figure 6. 


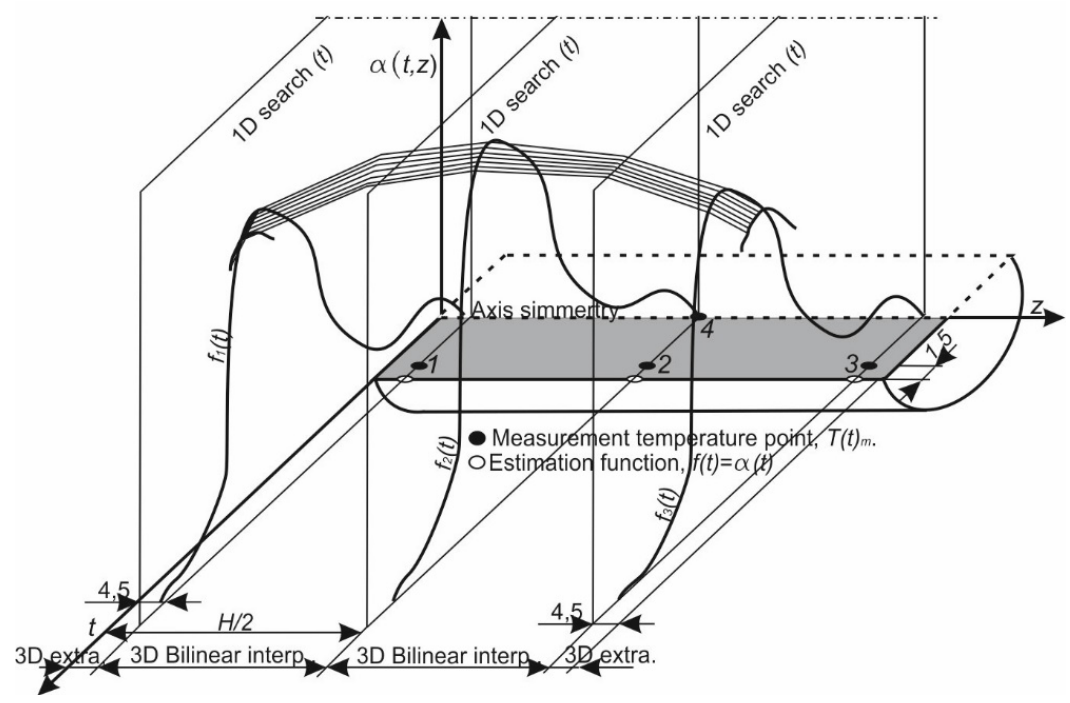

Fig. 6 Position of search points $\alpha(t)=f_{i}(t), i=1,2,3$

Figure 6 shows three parallel 1D search points in the function of the probe height $z$ at one time interval $\left(t_{1}, \ldots . t_{k}\right)$, [9]. The $k$ number represents carefully chosen discontinuous time steps in which the heat transfer coefficient is to be found. An example of quantitative search results is the text grid files given in Figure 7.

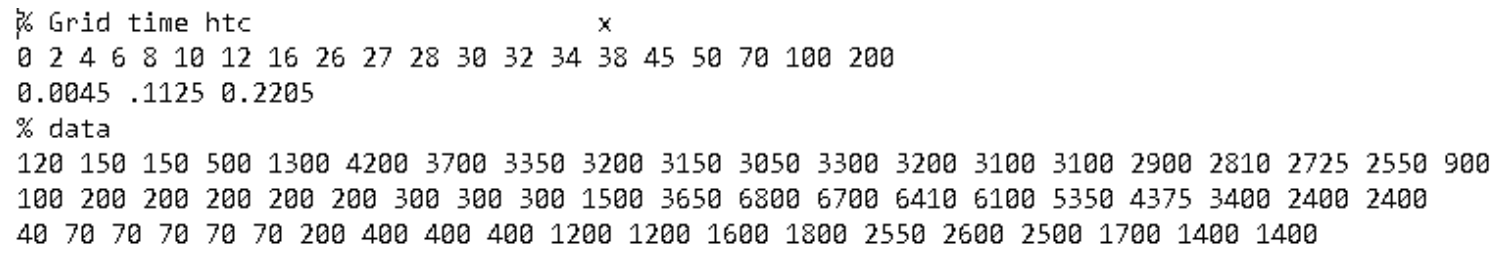

Fig. 7 Text grid file of the search results of a heat transfer coefficient during probe quenching $\phi 75 \times 225$ in $5 \%$ Aquatensid BW water $40{ }^{\circ} \mathrm{C}$

The first row represents the searching time in seconds while the second row represents the three heights of $z$ probe in metres. The last three rows present the time functions $f_{l}(t), f_{2}(t)$ and $f_{3}(t)$ in $\mathrm{W} /\left(\mathrm{m}^{2} \mathrm{~K}\right)$. The explanation of the $1 \mathrm{D}$ search of heat transfer coefficient, the number of Pareto fronts with the corresponding number of local optimums as a result of the non-dominant sorting genetic algorithm (NSGA II) was given in details in [7] and [8].

\section{Analysis and comparison of the obtained results}

In the paper [1] the results of water quenching at $40{ }^{\circ} \mathrm{C}$ as the most intensive item for steel quenching were given. This paper gave the results of quenching in aqueous solutions that show a slower cooling intensity compared to the cooling intensity in pure water. The point 2 was selected for comparison from the probe $\phi 25 \times 100$ and given in Figure 8 while Figure 9 shows a comparison of cooling rates also in point 2. 


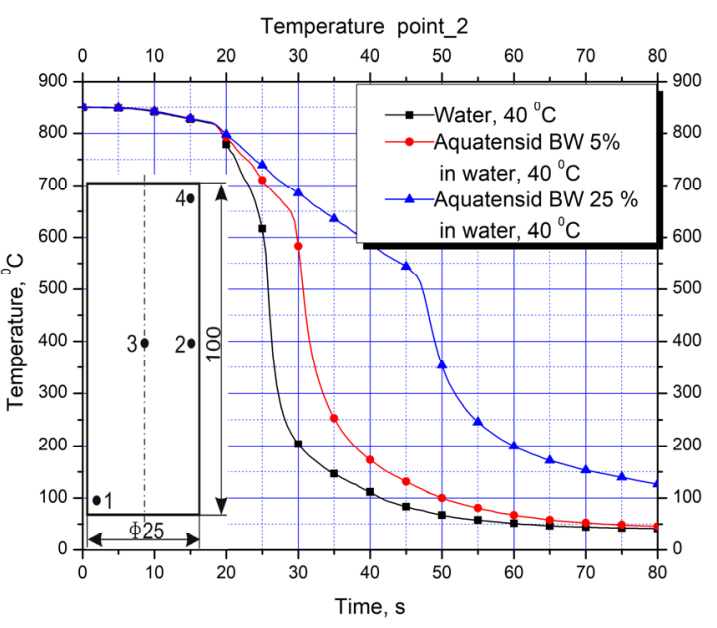

Fig. 8 Temperatures experimental results at point 2 of cylinder $\phi 25 \times 100$ in water and aqueous solutions of Aquatensid BW at $40^{\circ} \mathrm{C}$

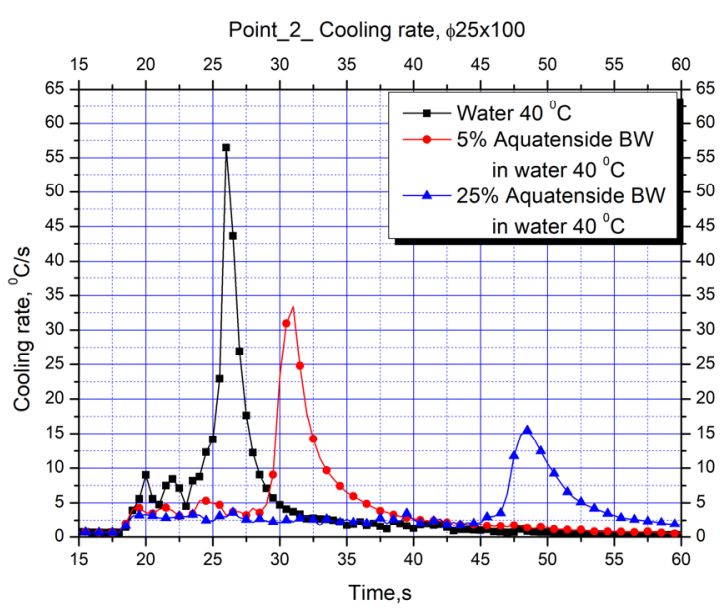

Fig. 9 Cooling rates experimental results at point 2 of cylinder $\phi 25 \times 100$ in water and aqueous solutions of Aquatensid BW at $40{ }^{\circ} \mathrm{C}$

A comment for the comparison of the maximum cooling rates from Figure 9 at point 2 was given in the conclusion of the paper.

\subsection{Results of the probe $\phi 25 \times 100$ quenching}

The results of the 1D search for the heat transfer coefficient for three values of the axis $z$ in the probe $\phi 25 \times 100$ in $5 \%$ and $25 \%$ of the Aquatensid in the water at $40{ }^{\circ} \mathrm{C}$ were shown in Figures 10 and 11.

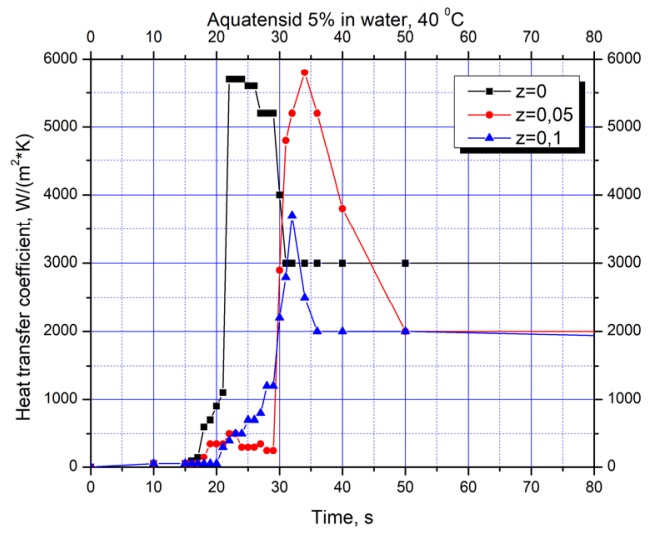

Fig. 10 Time functions $f_{l}(t), f_{2}(t)$ and $f_{3}(t)$ at points $1,2,4$ of the $\phi 25 \times 100$ probe in $5 \%$ Aquatensid BW water at $40^{\circ} \mathrm{C}$

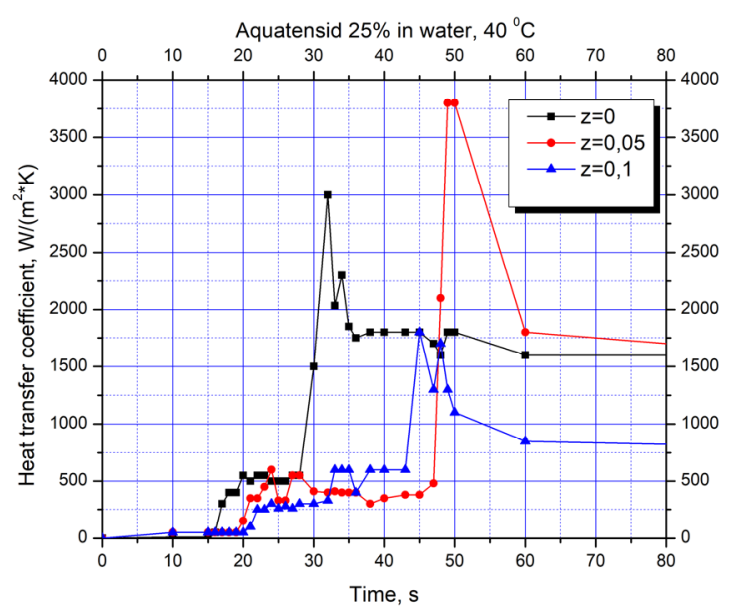

Fig. 11 Functions $f_{1}(t), f_{2}(t)$ and $f_{3}(t)$ in marked points of the $\phi 25 \times 100$ probe in $25 \%$ Aquatensid BW water at $40{ }^{\circ} \mathrm{C}$

Subsequently, the parametric curves in Figures 10 and 11 are 3D linearly interpolated/extrapolated to the function $\alpha(t, z)$, that is, the heat transfer coefficient and in this form was imposed on the outer surfaces of the cylinder. A sufficient accuracy of the heat transfer coefficient $\alpha(t, z)$ can be seen on the comparison of the measured and simulated temperature values in time at the four same points of the test cylinder in Figures 12 and 13. 


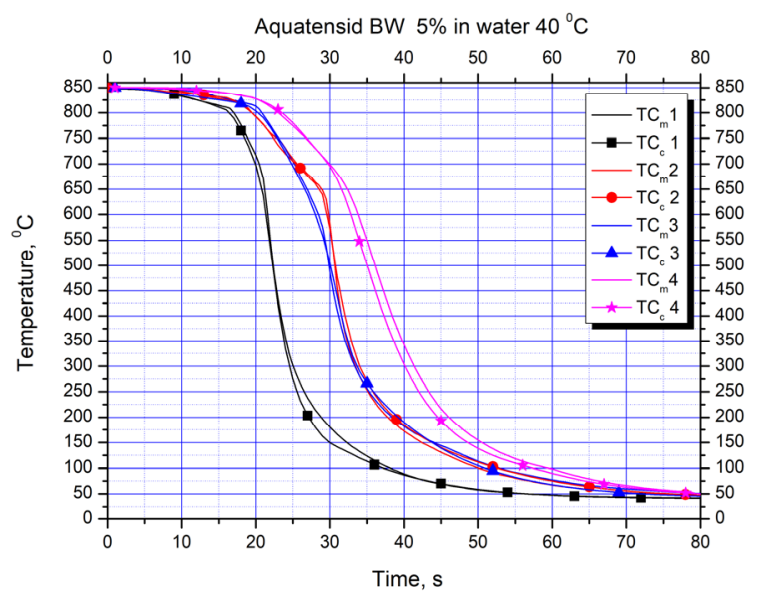

Fig. 12 Comparison of simulated and measured temperatures at points $1,2,3,4$ of the $\phi 25 \times 100$ probe in $5 \%$ Aquatensid $\mathrm{BW}$ water at $40{ }^{\circ} \mathrm{C}$

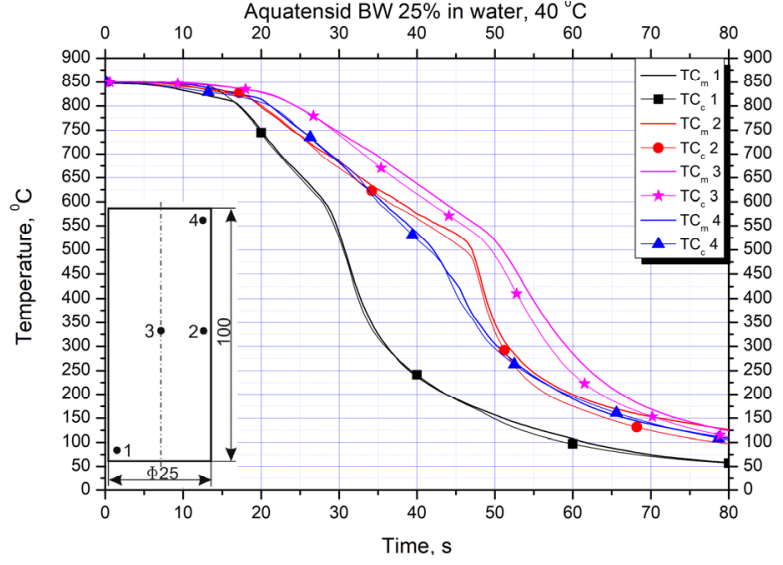

Fig. 13 Comparison of simulated and measured temperatures in marked points of the $\phi 25 \times 100$ probe in $25 \%$ Aquatensid BW water at $40{ }^{\circ} \mathrm{C}$

In Figures 12 and 13 the $\mathrm{TC}_{\mathrm{m}}$ and $\mathrm{TC}_{\mathrm{c}}$ symbols present thermocouple measurement or thermocouple calculation at the marked points of individual probes. The largest local deviation in Figure 12 is $30{ }^{\circ} \mathrm{C}(3.5 \%)$ and is seen at the central measuring point. Other cooling curves locally deviate from less than $2.5{ }^{\circ} \mathrm{C}(2.9 \%)$. In Figure 13 the largest deviation is $41{ }^{\circ} \mathrm{C}(4.8 \%)$ in the central measuring point. Other cooling curves deviate about $25{ }^{\circ} \mathrm{C}$ $(2.9 \%)$ which is still within acceptable limits, below $3 \%$. The calculated temperatures are the result of the solving algorithm based on minimisation of the measured and calculated temperatures' square deviation. After the calculation, the percentage of the temperature local deviation was obtained as a linear difference between the measured and calculated temperature results in one position and moment of time.

\subsection{Results of the probe $\phi 50 \times 150$ quenching}

Figures 14 and 15 give the heat transfer coefficient results in time for three $z$ axis values while quenching the $\phi 50 \times 150$ probe in $5 \%$ and $25 \%$ Aquatensid in the water at $40{ }^{\circ} \mathrm{C}$.

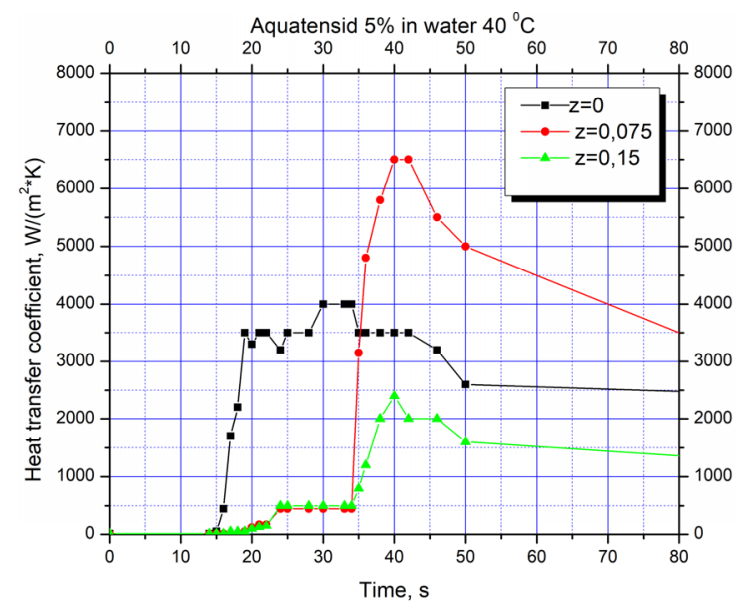

Fig. 14 Time functions $f_{l}(t), f_{2}(t)$ and $f_{3}(t)$ at points $5,6,8$ of the $\phi 50 \times 150$ probe in $5 \%$ Aquatensid BW water at $40^{\circ} \mathrm{C}$

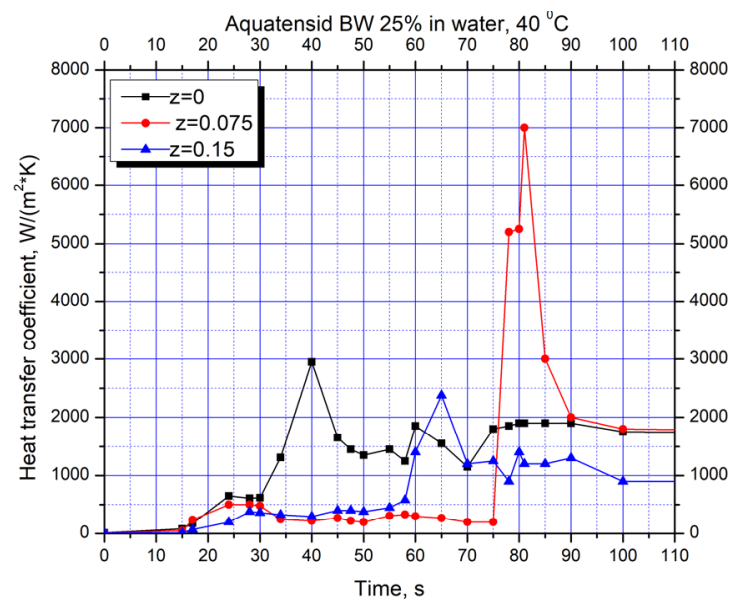

Fig. 15 Time functions $f_{l}(t), f_{2}(t)$ and $f_{3}(t)$ in marked points of the $\phi 50 \times 150$ probe in $25 \%$ Aquatensid BW water at $40{ }^{\circ} \mathrm{C}$

Comparison of measured and simulated temperature values in time at the four same test points of $\phi 50 \times 150$ cylinder was given in Figures 16 and 17. 


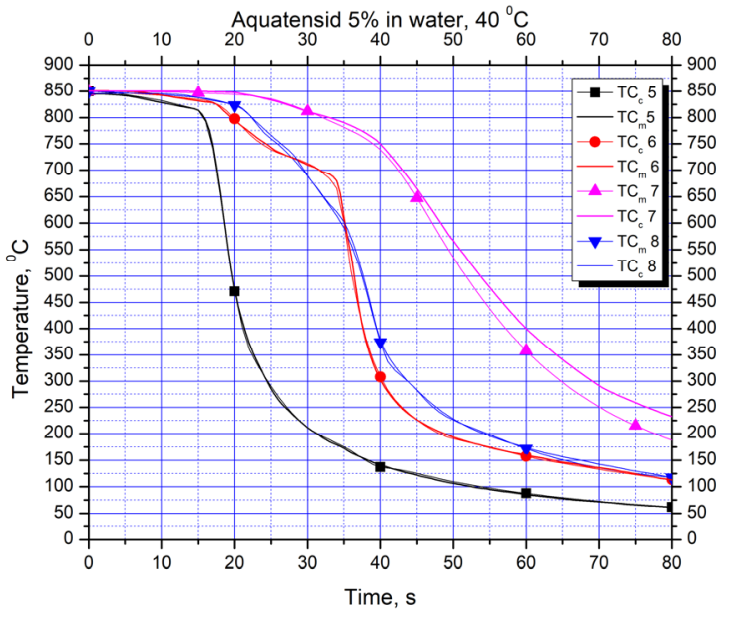

Fig. 16 Comparison of simulated and measured temperatures at points $5,6,7,8$ of the $\phi 50 \times 150$ probe in $5 \%$ Aquatensid $\mathrm{BW}$ water at $40{ }^{\circ} \mathrm{C}$

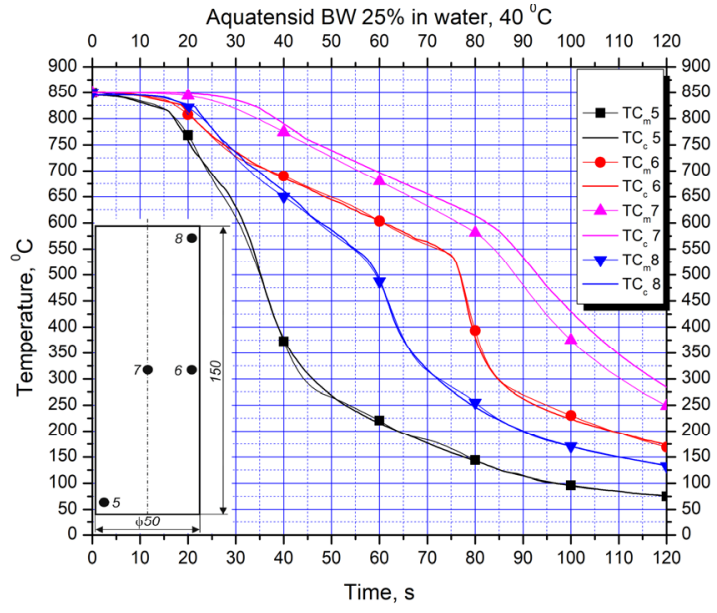

Fig. 17 Comparison of simulated and measured temperatures in marked points of $\phi 50 \times 150$ probe in $25 \%$ Aquatensid $\mathrm{BW}$ water at $40{ }^{\circ} \mathrm{C}$

In Figure 16 the maximum deviation was $38^{\circ} \mathrm{C}(4.4 \%)$ in the central measuring point. Other cooling curves locally deviate less than $13{ }^{\circ} \mathrm{C}(1.5 \%)$. The deviation in Figure 17 was $40{ }^{\circ} \mathrm{C}$ $(4.7 \%)$ in the central point. The other cooling curves deviate less than $13{ }^{\circ} \mathrm{C}(1.5 \%)$.

\subsection{Results of the probe $\phi 75 \times 225$ quenching}

The parametric results of the search for the heat transfer coefficient in time for three values of the $z$ axis at $\phi 75 \times 225$ probe quenching in 5\% and $25 \%$ Aquatensid in the water at $40{ }^{\circ} \mathrm{C}$ were given in Figures 18 and 19.

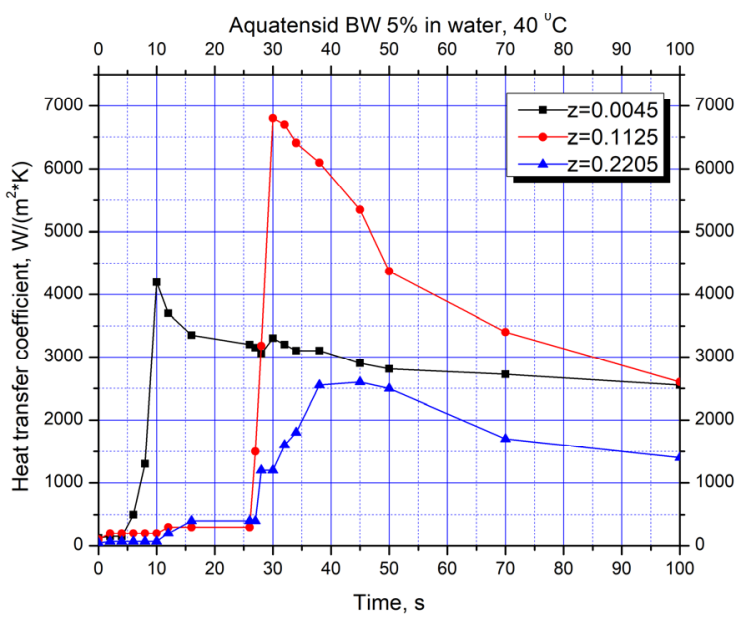

Fig. 18 Time functions $f_{l}(t), f_{2}(t)$ and $f_{3}(t)$ at points $9,10,12$ of the $\phi 75 \times 225$ probe in $5 \%$ Aquatensid BW water at $40{ }^{\circ} \mathrm{C}$

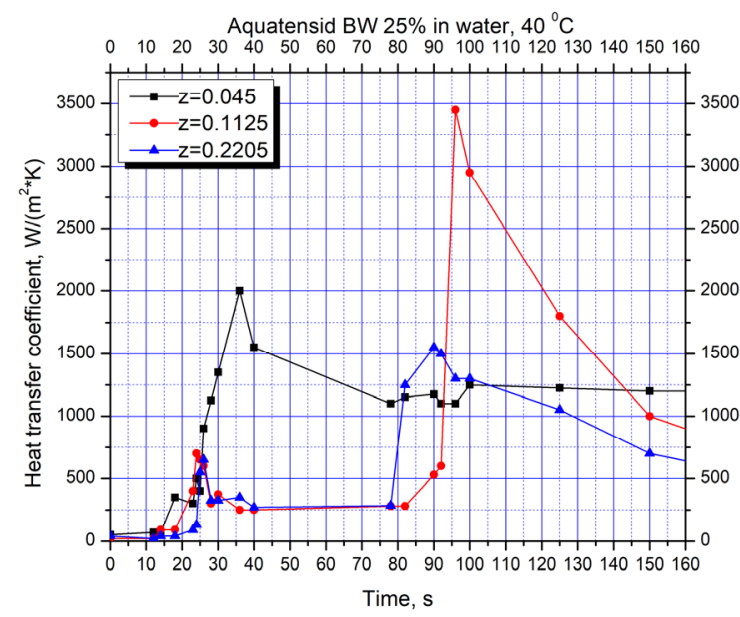

Fig. 19 Time functions $f_{l}(t), f_{2}(t)$ and $f_{3}(t)$ in marked points of the $\phi 75 \times 225$ probe in $25 \%$ Aquatensid water at $40{ }^{\circ} \mathrm{C}$

Figures 20 and 21 give a comparison of the measured and simulated values of temperature in time at the four same points of the $\phi 75 \times 225$ test cylinder. 


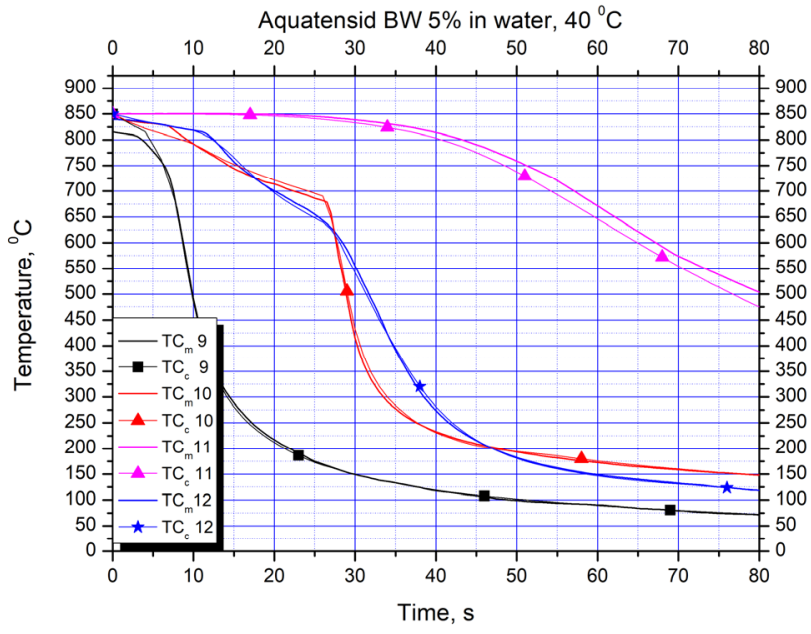

Fig. 20 Comparison of the simulated and measured temperatures at points $9,10,11,12$ of the $\phi 75 \times 225$ probe in $5 \%$ Aquatensid $\mathrm{BW}$ water at $40{ }^{\circ} \mathrm{C}$

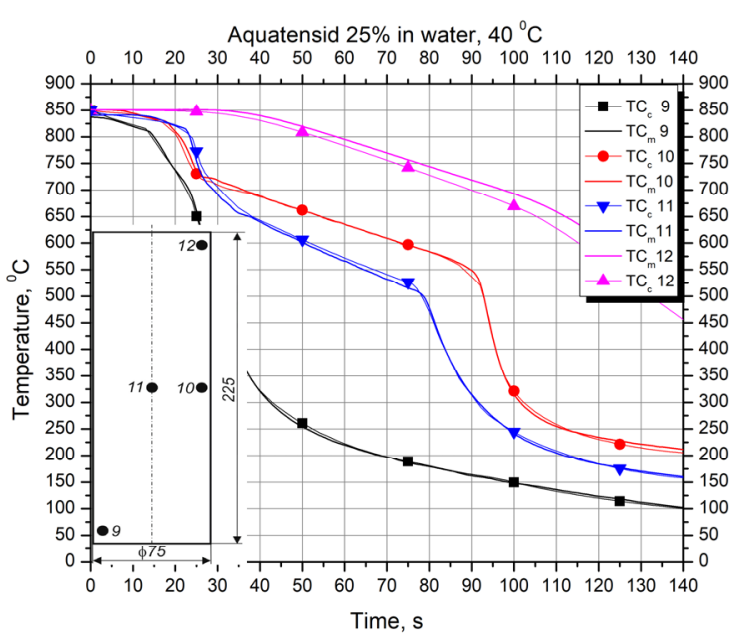

Fig. 21 Comparison of the simulated and measured temperatures in marked points of the $\phi 75 \times 225$ probe in $25 \%$ Aquatensid BW water at $40{ }^{\circ} \mathrm{C}$

The largest deviation in Figure 20 is $35^{\circ} \mathrm{C}(4,1 \%)$ at the central measuring point. The cooling curves near the outer surface deviate less than $15{ }^{\circ} \mathrm{C}(1.7 \%)$. In Figure 21 the maximum deviation is $40{ }^{\circ} \mathrm{C}(4.7 \%)$ at the central measuring point while the other cooling curves deviate from less than $13{ }^{\circ} \mathrm{C}(1.5 \%)$.

\section{Conclusion}

The obtained solutions of the heat transfer coefficient were reflected by the deviation of the measured and simulated cooling curves. Significant deviations were shown at the central measuring point for each simulation. The maximum value of this deviation was $4.8 \%$. Other measuring points were below acceptable 3\%. Figures 12 and 13 attempted to increase accuracy at the central point of the probe but the accuracy in points that are close to the outer surface of the probe deteriorated and they were the ones that were relevant for the heat transfer coefficient algorithm. The worsened accuracy meant that the temperature changes that came from the surface of the test probe had the slowest sensitivity on the cooling curve at the centre point while the cooling curves at three points near the outer surface of the probe had very fast sensitivity to these changes. The deviation in the measured and calculated cooling curves can be attributed to the assumptions introduced in the computational model. In Figure 12 in point 2, by comparing the maximum cooling rates, it can be seen that the aqueous solution with 5\% of Aquatensied BW 1.7 times more slowly cools from pure water under completely equal quenching conditions. The solution with $25 \%$ of Aquatensid BW in water 2.3 times more slowly cools from pure water at the same point and also under the same quenching conditions. Pure water has a very significant steam film dynamics, [1] so the solution algorithm requires a wider number of search time steps in the intervals of large temperature gradients in order to more accurately capture the local extremes of the heat transfer coefficient. The number of search time steps for Aquatenside BW in water was less frequent because the area of periodic creation and disappearance of the steam film was minimised and the duration of periodic steam films was longer. In the figures of the cooling curves, especially in Figure 21, a time interval of steam film stability was clearly visible which completely surrounds the test probe and another of its fast peeling or the transition to the bubble evaporation zone. 
This feature of Aquatensid BW in water is especially suitable for the thermal treatment of steel because the surface of the steel remains bright and smooth after the quenching.

\section{REFERENCES}

[1] Behrem Š., Hrnjica B., Estimation of heat transfer coefficient during quenching steel in water, TRANSACTIONS OF FAMENA XLII- Special issue 1 (2018), ISSN 1333-1124, eISSN 1849-1391. https://doi.org/10.21278/TOF.42Si106

[2] Galović, A., Contribution to the theory of heat transfer between the fluidized baths and immersed solid wall, Phd Thesis, Faculty of Mechanical Engineering and Naval Architecture, Zagreb, 1985.

[3] Liščić, B. and Tensi H.M, Luty W., Theory and Technology of Quenching, Springer-Verlag, 1992. https://doi.org/10.1007/978-3-662-01596-4

[4] Behrem, Š., Impact kinematics wetting and diameter cylindrical probe on Heat transfer coefficient during quenching of steel, Phd Thesis, University of Bihac, Faculty of Technical Enginerinng, 2015.

[5] Felde, I., Réti, T., Sarmiento, G., Smoljan B. and A. Deus, Analysis of a numerical method developed for estimation of the heat transfer coefficient obtained during quenching, NETSU SHORI Journal of the Japan Society for Heat Treatment, Vol. 49 (2), 2009, p. 816-819.

[6] Felde, I., Estimation of Thermal Boundary Conditions by using Hybrid Inverse Approach, Materials Science Forum, ISSN: 1662-9752. Vol. 812. pp 419-424, 2015.

https://doi.org/10.4028/www.scientific.net/msf.812.419

[7] Deb, K., Multi-Objective Optimization using Evolutionary Algorithms, Wiley, West Sussex, United Kingdom. 2009.

[8] Özisik, M. N. and Orlande, H. R. B., Inverse heat transfer fundamentals and applications, Department of Mechanical and Aerospace Engineering, North Carolina, State University, 2000.

[9] Bahrudin Hrnjica 1, Ali Danandeh Mer 2, Šefik Behrem 3, Necati Ağıralioğlu 4, Genetic programming for turbidity prediction: daily and monthly scenarios, International Symposium on Urban Water and Wastewater Management, October 25-27, 2018, Denizli

Submitted: $\quad$ 16.09.2019

Accepted: $\quad 29.10 .2020$
Assist. Prof. Šefik Behrem Assist. Prof. Bahrudin Hrnjica University of Bihac, Faculty of Technical Engineering Dr. Irfana Ljubijankića bb., 77000 Bihać Bosnia and Herzegovina 